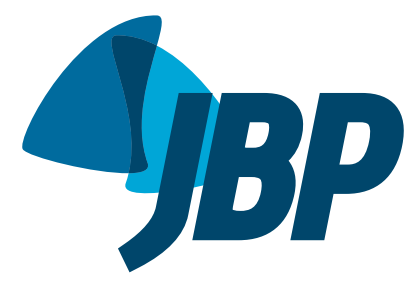

\title{
Cervical computed tomography in patients with obstructive sleep apnea: influence of head elevation on the assessment of upper airway volume
}

\author{
Shailendra Singh Rana', Om Prakash Kharbanda'
}

We read with great interest the article by Souza et al. ${ }^{(1)}$ describing cervical $\mathrm{CT}$ in patients with obstructive sleep apnea (OSA) and the influence of head elevation on the assessment of upper airway volume. We congratulate the authors for choosing such a meaningful topic and using cone beam CT. In their study, ${ }^{(1)}$ CT scans were obtained with the head of the patient in two positions (neutral and at a $44^{\circ}$ upward inclination). Polysomnography was used for diagnosing the patients with OSA. During polysomnography, the nasal pressure transducer channel or the thermistor channel (oral or nasal) are used for monitoring airflow from the nasal cavity. The nasal cavity is bounded anteriorly by the nostrils and posteriorly by the posterior border of the nasal septum (choanae). (2) The nasal airway comprises nearly two thirds of airway resistance during normal breathing ${ }^{(3)}$ and engorgement of nasal turbinate blood vessels, septum deviation, polyps, and other mucosal abnormalities due to chronic inflammation worsen nasal obstruction. ${ }^{(4)}$

The anatomical definition of upper airway includes both the pharynx and the nasal cavity. ${ }^{(5)}$ The combination of nasal obstruction and that of the oropharynx leads to a two-fold increase in the risk of having OSA, when compared with patients with no nasal obstruction. ${ }^{(6)}$ In the study by Souza et al., (1) airway volume was measured from the hard palate to the base of the epiglottis using CT images, which means that the nasal volume was not considered. These methodological limitations of the study would lead to an erroneous representation in the title of the study and in the discussion of the results. The authors may like to dwell upon this inconsistency for the benefit of readers.

\section{REFERENCES}

1. Souza FJ, Evangelista AR, Silva JV, Périco GV, Madeira K. Cervical computed tomography in patients with obstructive sleep apnea: influence of head elevation on the assessment of upper airway volume. J Bras Pneumol. 2016;42(1):55-60. http://dx.doi.org/10.1590/S180637562016000000092

2. Jaeger JM, Blank RS. Essential anatomy and physiology of the respiratory system and the pulmonary circulation. In: Slinger $\mathrm{P}$, editor. Principles and Practice of Anesthesia for Thoracic Surgery. New York: Springer; 2011. p. 51-69. http://dx.doi.org/10.1007/978-1-4419-0184-2_4

3. FERRIS BG Jr, MEAD J, OPIE LH. PARTITIONING OF RESPIRATORY
FLOW RESISTANCE IN MAN. J Appl Physiol. 1964;19:653-8.

4. Georgalas $C$. The role of the nose in snoring and obstructive sleep apnoea: an update. Eur Arch Otorhinolaryngol. 2011;268(9):1365-73. http://dx.doi.org/10.1007/s00405-010-1469-7

5. Morris IR. Functional anatomy of the upper airway. Emerg Med Clin North Am. 1988;6(4):639-69.

6. Liistro G, Rombaux P, Belge C, Dury M, Aubert G, Rodenstein DO. High Mallampati score and nasal obstruction are associated risk factors for obstructive sleep apnoea. Eur Respir J. 2003; 21(2):248-52. http://dx.doi. org/10.1183/09031936.03.00292403 


\section{AUTHORS' REPLY}

\section{Fábio José Fabrício de Barros Souza', Anne Rosso} Evangelista ${ }^{2}$, Juliana Veiga Silva ${ }^{2}$, Grégory Vinícius Périco $^{3}$, Kristian Madeira ${ }^{4,5}$

In our study of cervical CT in patients with OSA, we found that airway volume increased by $7.9 \mathrm{~cm}^{3}(17.5 \%)$ when a $44^{\circ}$ upward inclination was compared with a neutral head position..$^{(1)}$ Our results are reliable and show statistically significant differences despite the small sample size. ${ }^{(1)}$ The title states that the study involved cervical CT rather than CT with analysis of nasal airway volume. In the studies of imaging evaluation of airway volume cited in the Discussion section of our study, airway volume was measured from the hard palate to the base of the epiglottis for analysis of interventions involving a mandibular advancement splint, maxillomandibular advancement surgery, and continuous positive airway pressure. ${ }^{(1)}$ The clinical foundation for our study was provided by a previous study of OSA patients undergoing polysomnography; in that study, which was cited in our article, the apnea-hypopnea index was measured at baseline (i.e., during standard polysomnography) and after elevation of the head of the bed, the latter having resulted in a reduction in the apnea-hypopnea index.(1) A possible functional explanation is that head elevation contributes to upper airway patency, prevents rostral fluid shift, and averts tongue collapse, reducing upper airway resistance, changing upper airway critical pressure, affecting gravitational effects, and altering neuromuscular activity. ${ }^{(1)}$
The late Professor Bruno Carlos Palombini (a notable Brazilian pulmonologist) coined the term "viaerologia" ("airwayology") to describe an integrated view of airway diseases in the fields of pulmonology, otorhinolaryngology, gastroenterology, and sleep medicine, advocating the importance of the anatomical and functional attributes of the airway. ${ }^{(2)}$ Diseases such as OSA have multiple phenotypic characteristics, which were not fully addressed in our study.

In patients with OSA, the role of the nasal cavity is extremely important not only in clinical analysis but also in the apnea-hypopnea index. Nasal anatomic factors, appropriately pointed out by Rana \& Kharbanda, can cause significant resistance and be a contributing factor to OSA. To our knowledge, there have been no studies involving nasal imaging with and without head elevation in patients with OSA. The anatomical region of interest in our study is similar to that used in most studies involving imaging evaluation of upper airway volume and evaluating therapeutic interventions. In addition, we sought to assess upper airway volume in a site in which collapsibility is increased; CT scans of patients sitting upright or lying supine have shown that the highest degree of variation with the postural change was in the oropharynx. ${ }^{(3)}$ Anatomical changes with fixed nasal obstruction, such as septal deviation and polyps, are likely to vary little with postural changes. However, patients with intranasal edema might benefit from head elevation, a hypothesis that should be explored in future studies.

\section{REFERENCES}

1. Souza FJ, Evangelista AR, Silva JV, Périco GV, Madeira K. Cervica computed tomography in patients with obstructive sleep apnea: influence of head elevation on the assessment of upper airway volume. J Bras Pneumol. 2016;42(1):55-60. http://dx.doi.org/10.1590/ S1806-37562016000000092

2. Palombini BC. Uma visão integradora. In: Palombini BC, Porto NS,

Araújo E, Godoy DV, editors. Doenças das vias aéreas: uma visão clínica integradora (Viaerologia). 1st ed. Rio de Janeiro: Revinter; 2001. p. 3-8.

3. Sutthiprapaporn $P$, Tanimoto $K$, Ohtsuka M, Nagasaki $T$, lida $Y$, Katsumata A. Positional changes of oropharyngeal structures due to gravity in the upright and supine positions. Dentomaxillofac Radiol. 2008;37(3):130-5. http://dx.doi.org/10.1259/dmfr/31005700

\footnotetext{
1. Disciplina de Pneumologia, Curso de Medicina, Universidade do Extremo Sul Catarinense - UNESC - Criciúma (SC) Brasil.

2. Curso de Medicina, Universidade do Extremo Sul Catarinense - UNESC - Criciúma (SC) Brasil.

3. Unidade Radiológica Criciúma, Criciúma (SC) Brasil.

4. Disciplina de Bioestatística, Curso de Medicina, Universidade do Extremo Sul Catarinense - UNESC - Criciúma (SC) Brasil.

5. Laboratório de Epidemiologia, Curso de Medicina, Universidade do Extremo Sul Catarinense - UNESC - Criciúma (SC) Brasil.
} 